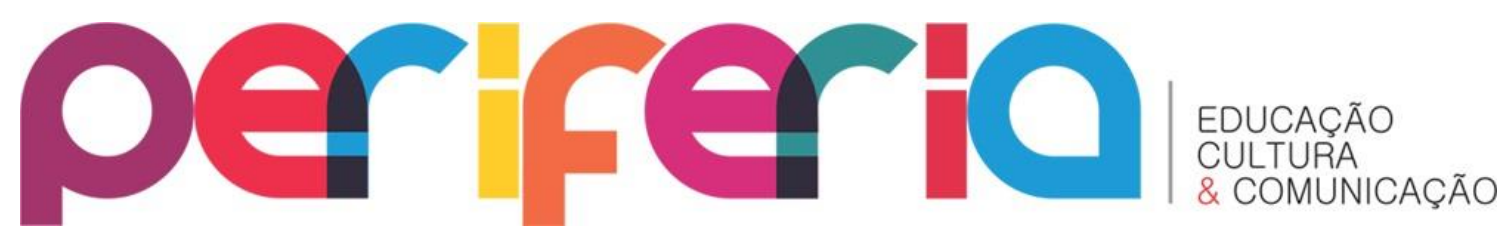

\title{
PRÁTICAS CONSERVADORAS: SUAS INFLUÊNCIAS NAS TESSITURAS IDENTITÁRIAS DE GÊNEROS E SEXUALIDADES
}

\author{
Denize Sepulveda ${ }^{1}$ \\ Universidade do Estado do Rio de Janeiro - UERJ \\ José Antonio Sepulveda ${ }^{2}$ \\ Universidade Federal Fluminense - UFF
}

\section{Resumo}

O objetivo principal deste texto é demonstrar o conservadorismo presente na sociedade, mais especificamente na escola, principalmente no que concerne às manifestações de sexualidades e dos comportamentos dos gêneros. Para isso, analisou-se o caso de um alunx de uma escola pública do Estado do Rio de Janeiro vítima de práticas discriminatórias conservadoras e homofóbicas. Para desenvolver este trabalho, foi usado o paradigma indiciário de Carlo Ginzburg (1989), além do diálogo com autores como Foucault (2011, 2009, 2006, 1996, 1976), Goffmam (1988), Hirschmam (1992), Mannhein (1959) e Louro (2008). Como considerações finais entendeu-se que para lutar contra práticas conservadoras é preciso compreendê-las e discuti-las, de modo que a partir do debate alternativas democráticas possam ser pensadas. Assim, é preciso que encontremos caminhos possíveis para a tessitura de ações emancipatórias, uma vez que toda conquista democrática resulta de lutas que foram travadas contra o pensamento conservador, contra os poderes instituídos e suas formas de legitimação.

Palavras-chave: práticas; conservadorismo; tessituras identitárias

1 Professora do Programa de Pós-Graduação em Educação - FFP/UERJ.
denizesepulveda@hotmail.com
2 Professor do Programa de Pós-Graduação em Educação - PPGEDU/UFF.
jamsepulveda3@hotmail.com 


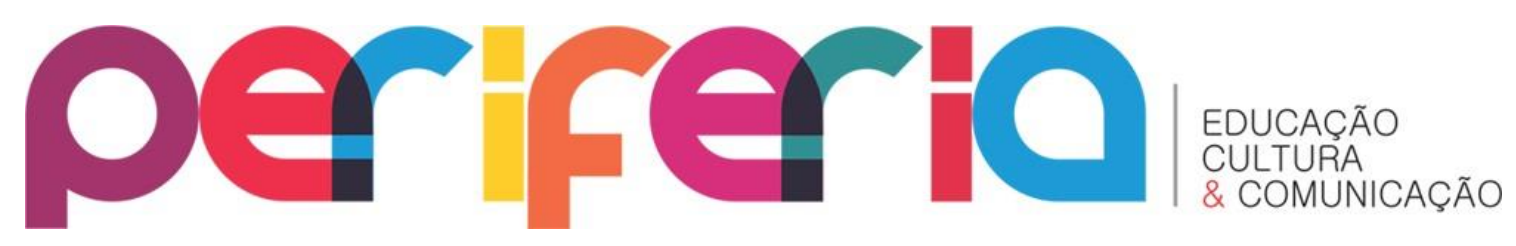

\title{
CONSERVATIVE PRACTICES: THEIR INFLUENCES IN THE IDENTITY TESTS OF GENES AND SEXUALITIES
}

\begin{abstract}
The main objective of this text is to demonstrate the conservatism present in the society, more specifically in the school, mainly in what concerns the manifestations of sexualities and the behaviors of the genders. For that, the case of a student of a public school in the State of Rio de Janeiro victim of conservative and homophobic discriminatory practices was analyzed. In order to develop this work, we used the Carlo Ginzburg (1989) indifference paradigm, as well as the dialogue with authors such as Foucault $(2011,2009$, 2006, 1996, 1976), (Goffmam, 1988), Hirschmam (1992), Mannhein 1959) and Louro (2008). As final considerations it was understood that in order to fight against conservative practices, it is necessary to understand them and discuss them in order that in the debate one can think of democratic alternatives.Thus, we must find possible ways for the fabrication of emancipatory actions. All democratic conquest is the result of struggles that have been fought against conservative thought, against instituted powers and their forms of legitimation.
\end{abstract}

Keywords: practices; conservatism; identity formation 


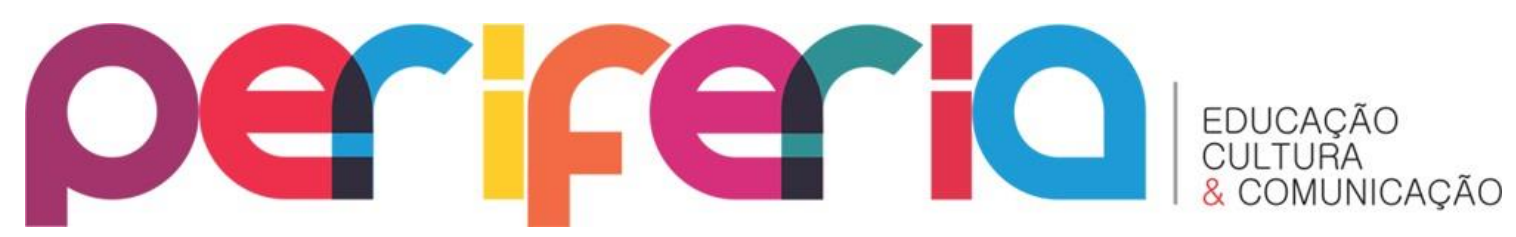

\section{INTRODUÇÃO}

Este texto tem por objetivo analisar a forma como o estilo de pensamento conservador age no processo de formação das identidades de gêneros e das identidades sexuais das pessoas que se afastam da norma padrão, considerada como ideal. Para isso, depois de uma reflexão sobre o conservadorismo, apresentamos um caso de exclusão escolar, fruto de nossa pesquisa realizada em uma escola pública do Estado do Rio de Janeiro.

Para efetivar este trabalho realizamos entrevistas e pesquisa participativa. Como metodologia, usamos o paradigma indiciário de Ginzburg (1989), a fim de encontrarmos pistas, indícios e sinais de práticas conservadoras nas escolas.

0 texto foi organizado em três partes. A primeira é uma discussão teórica sobre o que estamos entendendo como conservadorismo. Em seguida apresentamos o caso de um jovem vítima de discriminação conservadora e homofóbica ${ }^{3}$. E, por fim, fazemos algumas reflexões com o intuito de se pensar propostas de enfrentamento às tais práticas.

\section{O CONSERVADORISMO}

Desenvolver pesquisas sobre gêneros e sexualidades nos cotidianos das escolas se torna cada vez mais importante. Afinal, vivenciamos na realidade política brasileira um período extremante conservador que vem influenciando a educação brasileira. Segundo Hirschmam (1992), é difícil conceituar

\footnotetext{
${ }^{3} \mathrm{~A}$ homofobia é a atitude de hostilidade contra as/os homossexuais; portanto, homens ou mulheres. Segundo parece, o termo foi utilizado pela primeira vez nos EUA, em 1971; no entanto, ele apareceu nos dicionários de língua francesa somente no final da década de 1990: para Lê Nouveau Petit Robert, "homofóbico" é aquele que experimenta aversão pelos homossexuais. Mesmo que seu componente primordial seja, efetivamente, a rejeição irracional e, até mesmo, o ódio em relação a gays e lésbicas, a homofobia não pode ser reduzida a esse aspecto. Do mesmo modo que a xenofobia, o racismo ou antissemitismo, a homofobia é uma manifestação arbitrária que consiste em designar o outro como contrário, inferior ou anormal; por sua diferença irredutível, ele é posicionado a distância, fora do universo comum dos humanos (BORRILLO, 2010, p. 13).
} 


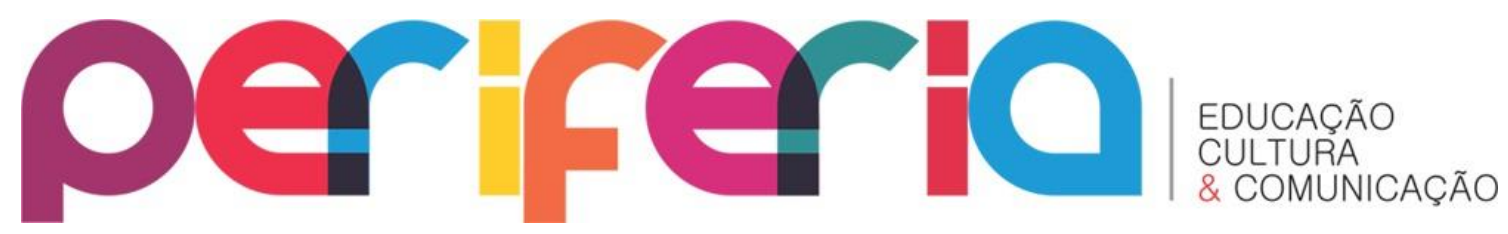

teoricamente o conservadorismo, mas é admissível identificar uma retórica do conservadorismo político, uma vez que essa se apresenta como enfrentamento a qualquer mudança no ordenamento político que possa, de alguma forma, transformar as relações de poder em uma sociedade. Para o autor existem três teses recorrentes da retórica conservadora: tese da perversidade, tese da futilidade e tese da ameaça.

De acordo com a tese da perversidade, qualquer ação proposital para melhorar um aspecto da ordem econômica, social, ou política só serve para exacerbar a situação que se deseja remediar. A tese da futilidade sustenta que as tentativas de transformação social serão infrutíferas, que simplesmente não conseguirão 'deixar uma marca'. Finalmente, a tese da ameaça argumenta que o custo da reforma ou mudança proposta é alto demais, pois coloca em perigo outra preciosa realização anterior (HIRSCHMAM,1992, p. 15).

Consideramos que o pensamento do Hirschmam (1992) não atende a totalidade da complexidade polissêmica da questão, uma vez que reduz a retórica conservadora a três teses. Contudo, ponderamos que essas teses são argumentáveis, pois não são usadas apenas pelxs ${ }^{4}$ conservadorxs, qualquer grupo pode usá-las, especialmente quando se tem partidos conservadores no poder. A problemática é a conjuntura e os desígnios pelos quais as referidas teses são empregadas. No momento que essas são usadas para impedir mudanças no ordenamento da sociedade ou para gerar melhoramentos reais para as classes trabalhadoras, ou para diverso grupo minoritário, temos uma retórica conservadora. É importante mencionar que nos momentos em que o conservadorismo do campo político discute temas de ordem moral ou comportamental, ele tende a defender os valores tradicionais.

Segundo Mannheim (1959), o conservadorismo nasce do tradicionalismo, portanto, tem um forte significado social e identitário. Nesse sentido,

\footnotetext{
${ }^{4} \mathrm{O}$ uso do "X" nas palavras, do ponto de vista linguístico e gramatical, é uma forma de usar uma linguagem escrita que expresse maior igualdade entre homens e mulheres.
} 


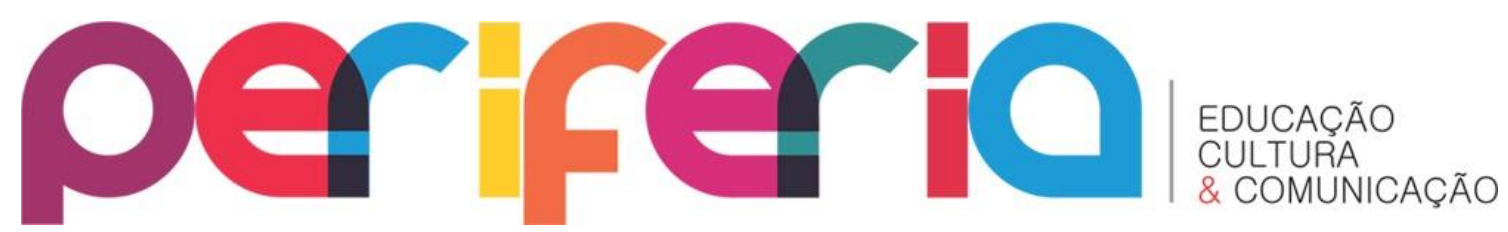

funciona como facilitador para que uma parcela da população se identifique com o seu discurso.

(...) o pensamento humano também se desenvolve em 'estilos' e há diferentes escolas de pensamento distinguíveis pelos diferentes modos como utilizam diferentes padrões e categorias de pensamento. (MANNHEIM, 1959, p. 79).

Assim, é necessário compreender que os estilos de pensamentos estão relacionados às diferentes classes sociais existentes, bem como as mudanças em um determinado estilo de pensamento também estão arroladas às alterações sociais que essas classes vivenciam.

Dessa forma, para auxiliar a nossa apreciação, é importante sinalizar que xs conservadores ao debaterem assuntos no campo político estão sempre contrários às minorias. Temas como direitos sexuais e reprodutivos, e descriminalização das drogas, estão continuamente no alvo dos discursos e da retórica dxs conservadorxs.

Segundo Foucault (1996), os discursos podem ser vistos funcionando como regimes de verdade ${ }^{5}$ e se baseiam em um sistema de exclusão, pois nem todxs possuem o direito ou a possibilidade de dizer tudo, assim como nem todxs são reconhecidxs em seus discursos. Ou seja, para xs conservadorxs só o seu discurso está autorizado, assim como apenas a sua forma de pensar é correta, excluindo, dessa forma, os demais discursos e pensamentos que são produzidos na arena social.

Certamente, se nos situarmos no nível de uma proposição, no interior de um discurso, a separação entre o verdadeiro e o falso não é nem arbitrária, nem modificável, nem institucional, nem violenta. Mas se nos situarmos em outra escala, se levantarmos a questão de saber qual foi, qual é

\footnotetext{
${ }^{5}$ Um dispositivo de verdade seria uma estratégia para compreender os jogos do poder que produzem as verdades e o falso, ou seja, é uma maneira de problematizar a produção do verdadeiro e do falso pelo Estado e presente na sociedade. A noção de regime de verdade também evoca visões do verdadeiro e do falso. Foucault (1996) explica que a verdade está sempre ligada a sistemas de poder que a produzem, e a resultados de poder que ela induz e que a reproduz. Dessa forma, não é apenas em relação aos discursos dominantes ou dominadores presentes na sociedade que faz sentido falar de regimes de verdade. 0 poder e a verdade estão interligados. A verdade é produzida pelo discurso numa relação de poder e este, por sua vez, opera em acoplamento com a verdade.
} 


\section{periferio}

constantemente, através de nossos discursos, essa vontade de verdade que atravessou tantos séculos de nossa história, ou qual é, em sua forma muito geral, o tipo de separação que rege nossa vontade de saber, então é talvez algo como um sistema de exclusão (sistema histórico, institucionalmente constrangedor) que vemos desenhar-se. (FOUCAULT, 1996, p. 14).

Xs conservadores, na ânsia de manter essa vontade de verdade, além de interditarem alguns discursos, muitas vezes os excluindo, também impõem à sociedade uma agenda conservadora, a qual, na prática, mantém seus valores. Assim, são exemplos da atual agenda conservadora no Brasil, as proibições das discussões de gênero e de orientação sexual nas escolas.

Essa agenda conservadora faz parte de um quadro de disputas que está presente em todos os campos sociais, mas que na educação vem se apresentando de forma impactante, principalmente na formação dxs alunxs LGBTIQS (Lésbicas, Gays, Bissexuais, Travestis, Transgêneros, Intersexuais, Queer e Simpatizantes ${ }^{6}$ ), uma vez que as medidas conservadoras, implementadas com as reformas, vêm causando reveses nesse segmento da sociedade, pois, para algunxs dessxs alunxs, o sentimento de baixa autoestima cresce consideravelmente, uma vez que passam a considerar errado ser lésbica, gay, bissexual, travesti, transgênero, intersexual ou simpatizante. Muitxs deixam de assumir suas identidades de gêneros e sexualidades, negando a si mesmos a possibilidade de vivenciarem sua sexualidade ou expressarem seus comportamentos de gêneros, o que os possibilitaria tecer de outras formas as suas identidades. Em outrxs, o enfretamento, assim como a luta pelo direito de exercer a diferença e de

\footnotetext{
${ }^{6}$ É necessário enfatizar que acrescentamos a letra "S" a referida sigla por considerarmos que os simpatizantes e parceiros dessas identidades também vivenciam em seus cotidianos procedimentos de discriminação, preconceitos e exclusão, são procedimentos diferentes, não são os mesmos, pois nenhum indivíduo sente esses processos da mesma forma, contudo sofrem essas ações. De acordo com Goffman (1988), as pessoas que compartilham da vida de indivíduos estigmatizados que sofrem processos de discriminação e preconceito, são definidos como seus iguais e denominados de "informados". São sujeitos cuja situação de vida ou militância os levou a serem simpatizantes da causa e que por isso possuem aceitação do grupo, por outro lado também sofrem da maior parte das privações, preconceitos e discriminações típicas do grupo pelo qual assumiram conviver e militar.
} 


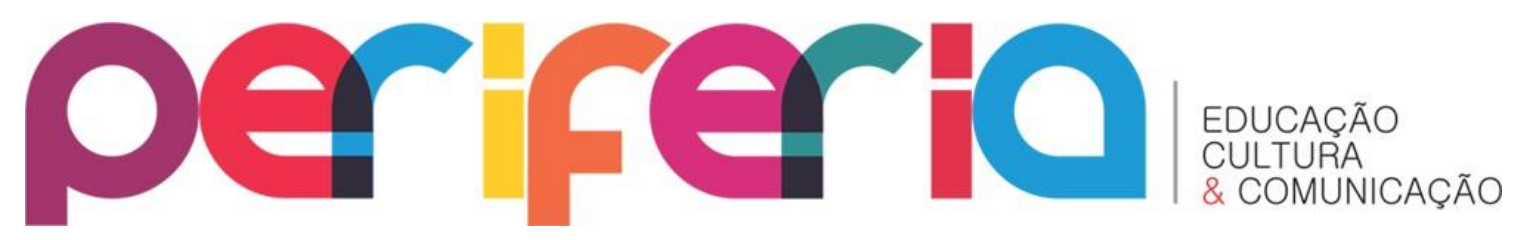

vivenciar suas sexualidades e comportamentos de gêneros, levam essxs estudantes a lutarem pela não discriminação, tornando-xs mais potentes.

Cada uma e cada um dessxs educandxs vão constituindo suas identidades de maneiras diferentes, de acordo com as experiências e conhecimentos que vão tecendo nos vários espaços e tempos de inserção social pelos quais passam, o que demonstra que todxs somos redes de sujeitos, como apontou Santos (2001). As experiências e os conhecimentos tecidos são diferentes de pessoa para pessoa e somos afetadxs de distintas formas, o que traz consequências de significação diversas para cada uma de nós.

Por isso, torna-se tão importante pensar sobre todas essas questões no campo da educação, pois a partir delas podemos discorrer sobre possibilidades de tessitura de conhecimentos que permitam que todxs xs alunxs possam vivenciar suas sexualidades e expressar seus gêneros. Portanto, não podemos deixar de pensar em algumas práticas pedagógicas conservadoras que ocorrem na escola, pois essas muitas vezes fundamentam processos de exclusão escolar e também fazem parte das redes que constituem xs alunxs, influenciando em suas tessituras identitárias.

Afirmamos, assim, a ideia de que os processos de exclusão escolar são práticas conservadoras e, como tal, podem causar danos aos processos de formação identitária daquelxs que são vitimados por esses processos em função daquilo que thes é constitutivo. Em geral, a pessoa excluída sente-se discriminada e estigmatizada, o que pode acabar por intervir negativamente na identificação de si própria. Na tessitura das identidades, o eu precisa do reconhecimento $\mathrm{dx}$ outrx para se reconhecer satisfatoriamente e de modo pleno. Se o reconhecimento $\mathrm{dx}$ outrx envolve procedimentos de discriminação e estigmatização, a tessitura das redes de sujeitos daquelxs que são submetidos a esses processos passa a contar com fios prejudiciais à saúde dos processos de formação, podendo gerar sentimentos e sensações negativas em relação a si mesmo. 


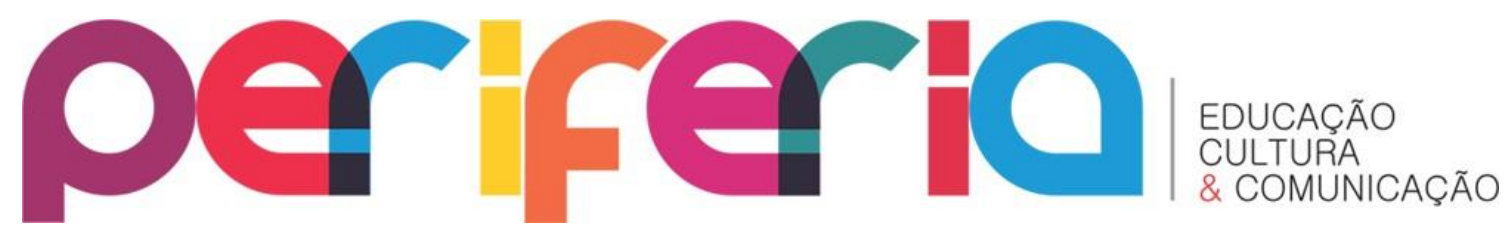

Algunxs estudantes LGBTIQS se sentem humilhadxs e discriminadxs. Como pudemos vivenciar em nossas pesquisas de campo, o sentimento de anormalidade está presente entre algunxs delxs e, também, na fala de algunxs professorxs. Segundo Foucault (2011), a anormalidade se constitui por meio de discursos, processos e práticas que produzem o metro-padrão, a formatação da vida, a governabilidade, e, em decorrência, produzem os diferentes. Esses discursos, processos e práticas são conservadores e levam à regulamentação do normal e do metro-padrão, assim como estabelecem os critérios de normalização, como a cura, a adaptação e a correção, fabricando concomitantemente os "anormais", ou seja, aqueles que fogem da forma e do padrão de normal.

Assim, percebemos que esses discursos, processos e práticas se apresentam como conservadores e produzem efeitos de verdade, fabricando, dessa forma, as identidades almejadas e uniformizadas. Entendemos que o sentimento de anormalidade, muitas vezes, está presente entre alunos LGBTIQS que sofrem processos de exclusão, o que interfere nos processos de produção das identidades dessxs estudantes.

Segundo Bauman (2005, p. 44), na atualidade, as pessoas que estão no polo privilegiado da hierarquia global emergente tecem e desarticulam as suas identidades mais ou menos à própria vontade. Todavia, as pessoas que se encontram no outro polo têm dificuldades para fazer valer seus desejos e modos próprios de tecer seus processos de formação identitária, não têm direito de manifestar suas preferências e são oprimidas por padrões conservadores identitários impostos por outrxs, "[...] identidades de que eles próprios se ressentem, mas que não têm per missão de abandonar nem das quais conseguem se livrar. Identidades que estereotipam, humilham, desumanizam, estigmatizam".

A partir do pensamento do autor, podemos inferir que xs alunas e os alunos LGBTIQS, que são vítimas de situações de discriminação e perseguição, são xs que têm negados os direitos à formação de suas identidades sexuais e identidades de gêneros, a elxs são oferecidas as identidades que 


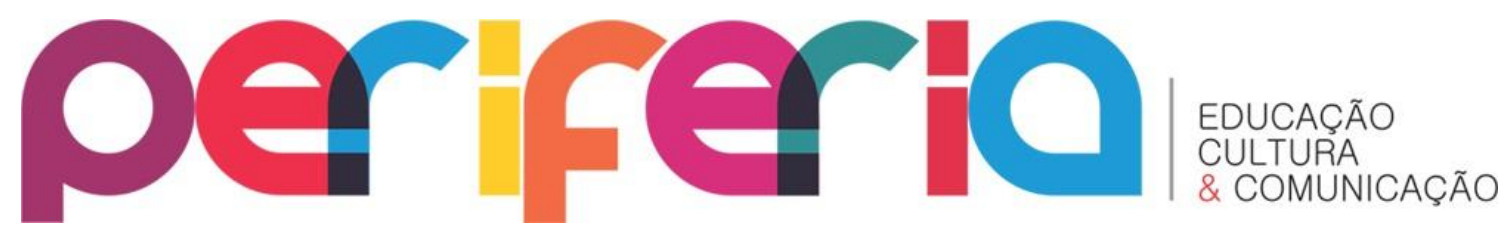

estereotipam, que humilham, que desumanizam e que estigmatizam, e essas, de alguma forma, vão influenciar na atuação posterior que ocuparão no espaço social.

Se você foi destinado à subclasse (porque abandonou a escola, é mãe solteira vivendo da previdência social, viciado ou exviciado em drogas, sem-teto, mendigo ou membro de outras categorias arbitrárias excluídas da lista oficial dos que são considerados adequados e admissíveis), qualquer outra identidade que você possa ambicionar ou lutar para obter the é negada a priori. O significado da "identidade da subclasse" é a ausência de identidade, a abolição ou negação da individualidade, do "rosto" - esse objeto do dever ético e da preocupação moral. Você é excluído do espaço social em que as identidades são buscadas, escolhidas, construídas, avaliadas, confirmadas ou refutadas. (BAUMAN, 2005, p. 46).

Assim, não podemos nos furtar de levar em conta os estudos que versam sobre as temáticas da diferença e da tessitura da identidade $\mathrm{dxs}$ alunxs LGBTIS que sofrem com algumas práticas conservadoras, pois essas xs levam a vivenciar situações de exclusões no cotidiano de algumas escolas. Nesse sentido, podemos pensar alternativas emancipatórias que possibilitem e proporcionem o direito à formação identitária pessoal, para além dos modelos preestabelecidos para todxs xs alunxs. É importante também tentar perceber as dificuldades e as incertezas que acompanham xs professorxs. Muitxs, apesar disso, procuram conhecer as diferenças que estão na escola, tentando, assim, aprender com elas. E nessa perspectiva de prosseguir aprendendo um pouco com as diferenças, a seguir tentaremos desinvisibilizar alguns processos de exclusão que se pautam no pensamento conservador. Narraremos, a partir da história de um estudante, processos que estereotipam, que humilham, que desumanizam e que estigmatizam possíveis formações identitárias.

\section{BERNARDO7 , O DESACREDITADO}

\footnotetext{
${ }^{7} \mathrm{O}$ nome do aluno foi alterado.
} 


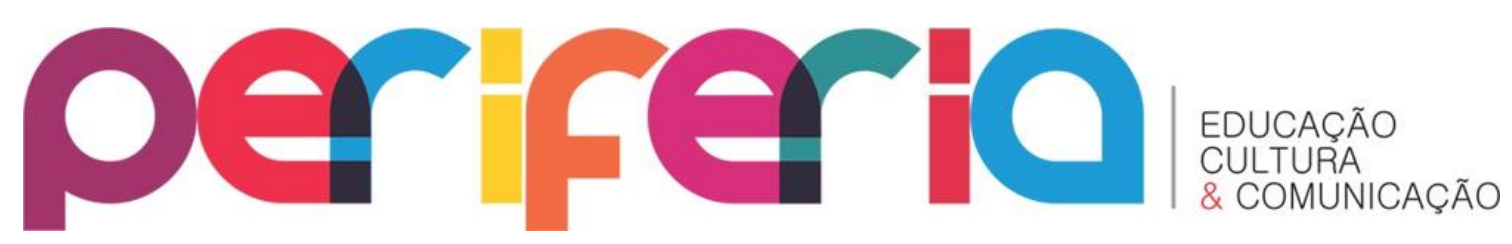

A história que passamos a contar aconteceu em 2009 no/com o cotidiano da escola ${ }^{8}$ onde desenvolvemos a pesquisa de campo. Ela não foi observada por nós pessoalmente, mas foi coletada em uma notícia bastante divulgada por um jornal do Estado do Rio de Janeiro, e em nossas primeiras observações algumas funcionárias e alguns funcionários comentaram o ocorrido.

O aluno Bernardo - adepto do candomblé e que foi para a escola vestido todo de branco, com o turbante e com as guias de santos - foi "expulso da sala de aula e chamado de filho do demônio por uma professora". O referido aluno, na época em que iniciamos nossas observações, era estudante do sétimo ano no turno da manhã e estava com dezesseis anos. Considerando que era aluno daquela instituição desde os cinco anos de idade, desde a educação infantil, era, portanto, estudante há doze anos. Durante 0 ano ${ }^{10}$ por nós observado, ele se afastou da escola por dois meses e, ao retornar, foi transferido depois de duas semanas para o turno da noite, a fim de participar do curso de aceleração; curso este que é frequentado pelxs alunxs que estão com a relação idade/série defasada.

$\mathrm{Na}$ ocasião, ao dar início as nossas conversas com algunxs funcionárixs da escola, foi-nos dito que a informação divulgada pela imprensa não era completamente verdadeira, pois, segundo elxs, o que motivou a expulsão do aluno não foi o traje do candomblé, mas sim o fato de ele utilizar elementos do candomblé para aterrorizar seus colegas. Maria ${ }^{11}$, uma das pessoas que conversou conosco, disse:

$\mathrm{Na}$ verdade, esse aluno já sofria discriminação por parte de seus colegas há muito tempo, mas não por ele ser adepto do candomblé, e sim por vir para a escola, desde muito pequeno, com mochila rosa, estojo rosa e com bonecas. Seu pai é homossexual e criou seu filho para ser homossexual. Foi essa

\footnotetext{
${ }^{8}$ Trata-se de uma escola pública pertencente a uma das redes de ensino do Estado do Rio de Janeiro.

9 Jornal O Extra, terça-feira, 27 de janeiro de 2009.

${ }^{10}$ A pesquisa foi desenvolvida na escola nos anos de 2009 a 2011.

11 O nome da funcionária foi alterado.
} 


\section{periferio}

aprendizagem que ele teve. Deus criou o homem para a mulher e a mulher para o homem, esse negócio de homossexualidade está fora dos padrões normais. Por causa disso os colegas o discriminavam, o chamavam de mulherzinha, bichinha e etc. A forma como ele lidou para conviver com essa situação foi amedrontá-los usando elementos do candomblé. Ele ficava falando para os colegas "cuidado que você vai virar cabra; o chifrudo vai vir de noite e vai pegar no teu pé; você vai virar galinha de despacho, cuidado que o diabo vê o que você está fazendo e vai te levar para viver com ele". Ele falava essas coisas assim... Nesse dia que aconteceu isso ele havia perturbado tanto os colegas que a professora perdeu a paciência.

Goffman (1988) diz que se constrói cultural e socialmente uma teoria do estigma para que se justifique a inferioridade pela qual se categorizou um determinado grupo. Historicamente, o termo estigma foi criado pelos gregos para designar sinais físicos, criados para marcar alguém ou alguma coisa que não se enquadrasse nos padrões de normalidade daquela sociedade. Em que pese ter adquirido outros significados, hoje em dia, entretanto, o termo tem um sentido parecido com o da antiguidade clássica, ou seja, existe como uma forma de rotulação depreciativa.

O referido autor menciona também que existem três tipos de estigma: em primeiro lugar existem os relacionados às abominações do corpo, em segundo, a culpa de caráter individual, e, por último, existem os estigmas tribais de raça, nação e religião. Em todos os modelos de estigma, incluindo até mesmo aqueles que os gregos tinham em mente, acham-se as mesmas características: uma pessoa que poderia ter sido prontamente recebida no contexto social cotidiano, mas que por ter um traço diferente, que chama a atenção, acaba por afastar aqueles que ela encontra, aniquilando a possibilidade de atenção para outras qualidades que apresente. É importante enfatizar que o estigma é uma marca identitária da diferença, que visa a uma inclusão perversa, pois passa a atuar incluindo a diferença no interior de um território identitário, ou seja, a estigmatização é um processo de reafirmação da diferença, mas que abole a sua inovação, já que tenta encaixá-la dentro dos parâmetros do que é considerado como normal ou anormal. O estigma 


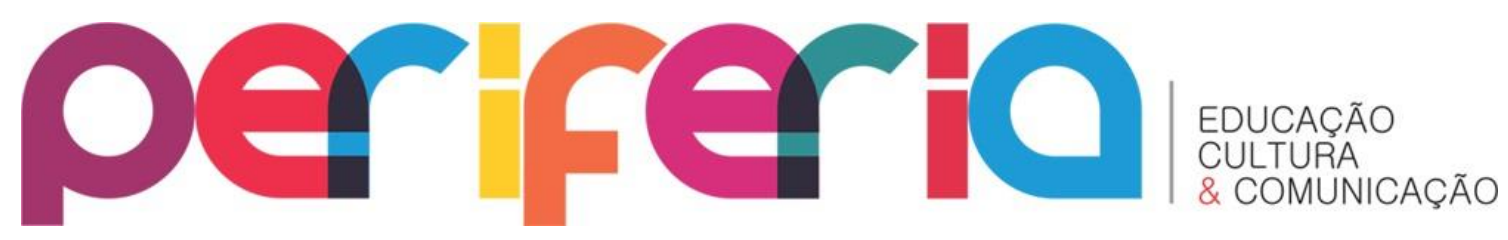

opera produzindo uma imagem de que o sujeito que o possui é anormal, pois possui uma diferença em relação às pessoas que são consideradas normais e que são semelhantes entre si. Portanto, $x$ estigmatizadx não é o semelhante às demais pessoas, elx é $x$ diferente.

A situação acima narrada nos dá pistas e sinais de que Bernardo possuía uma diferença que foi transformada em estigma - características diferentes, não previstas pela escola. Usava mochila rosa, estojo rosa e brincava com bonecas. Esses atributos nos soavam como indícios que impediram a escola de ver o jovem como um todo, taxando-o de homossexual, de maneira depreciativa, e utilizando sua sexualidade como justificativa para a discriminação que sofria.

Somos uma sociedade de enquadramento. Estabelecemos lugares para os sujeitos e para cada lugar definimos os comportamentos e as pessoas que lá podem estar. A sexualidade do sujeito atua como um marcador de lugar de identidade e de diferenças. Assim, podemos inferir que o comportamento e a orientação sexual do referido aluno não se enquadravam no encaixe conservador estabelecido pela instituição escolar e, portanto, o jovem passou por processos de estigmatização e subjetivação ${ }^{12}$.

[...] os gêneros são a primeira marcação identitária e de diferenças a que estamos expostos, ocorrendo antes mesmo de nascermos. Isso porque nascemos num mundo já organizado discursivamente e estabelecido na relação saber-poder. A pergunta "é menino ou é menina" inicia uma definição e uma diferença que nos enquadra, que nos marca, que nos organiza e que precisa de investimento para a sua concretização. Butler (2004) argumenta que, ao tratar essa sujeição e regulação ao gênero como algo que antecede ao nosso nascimento e marca nossas identidades, é importante levar em conta duas advertências advindas de Foucault. Por um lado, a ideia de que o poder regulador não atua somente sobre

\footnotetext{
${ }^{12}$ Segundo Foucault (2006) os processos de subjetivação fabricam e modelam os sujeitos; várias podem ser as instâncias, os dispositivos e os contextos onde o sujeito é fabricado ou modelado pelos processos de subjetivação, e o discurso é um desses dispositivos. Portanto, os processos de subjetivação são tanto causa quanto efeito dessa produção, eles se originam a partir de obrigações plurais pelas quais os indivíduos são formados pelos discursos de verdade, levando-os assim aos procedimentos que transformam seres humanos em sujeitos.
} 


\section{periferio}

esses sujeitos preexistentes, mas que ele forma o sujeito e, neste sentido, ele é produtivo. Por outro lado, estar sujeito a essas normas de gênero e sexualidade é também estar subjetivado por elas, num constante processo de construção. (FERRARI, 2010, p. 256).

A estigmatização leva ao deterioramento das relações $\mathrm{dx}$ suposto desviante com aquelxs que deveriam ser sexs "iguais", mas que se assumem como sexs essencialmente "diferentes", desqualificando-x e prejudicando as possibilidades de incorporação de novas expressões identitárias enriquecedoras da vida cotidiana em nome da manutenção do status quo. "Ela tem como efeito afastar o indivíduo da sociedade e de si mesmo de tal modo que ele acaba por ser uma pessoa desacreditada frente a um mundo não receptivo" (GOFFMAN, 1988, p. 28). Desacreditada porque a notícia que essa pessoa traz para a vida abala as verdades constituídas. Assim, desqualificar a nova expressão existencial é uma maneira que xs conservadorxs desenvolvem para tentar manter o status quo do já estabelecido. Podemos perceber que o aluno mencionado acima também era uma pessoa desacreditada perante a escola, pois a fala de Maria dá pistas de que a instituição escolar sabia que o estudante era discriminado pelos seus colegas. Porém, para ela, o que agravava a discriminação não era a religião e sim a suposta homossexualidade aliada à potência do bruxo. Ou seja, ele era desacreditado por causa de sua orientação sexual e essa justificava a discriminação que sofria. Se a aceitasse passivamente poderia permanecer, mas exercer potência em vez de aceitar o estigma que lhe buscavam imputar, era inaceitável. Podemos, ainda, pensar que outros fatores intervieram nesse processo, mas no contexto daquilo que aqui nos interessa, não vale a pena aprofundarmo-nos neles.

De certa forma, a escola permitiu que os procedimentos conservadores de enquadramento atuassem consentindo que Bernardo fosse expulso da sala de aula, punindo-o por causa de sua sexualidade e não aceitação do lugar que 


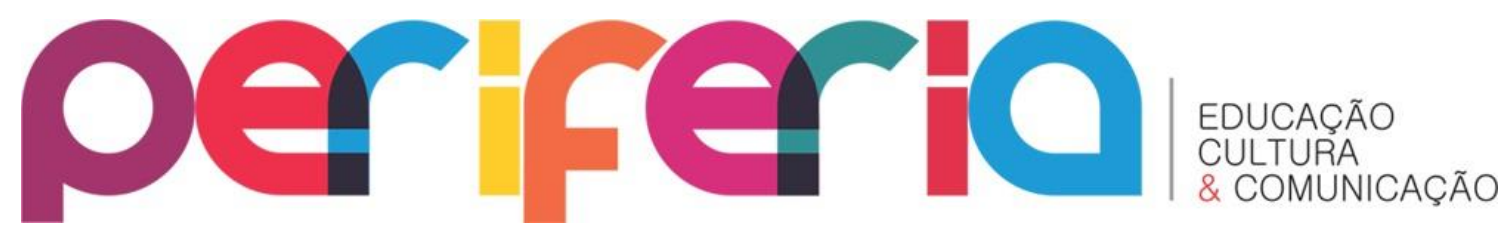

lhe estava destinado. Vemos, assim, dispositivos de poder ${ }^{13}$ atuando no cotidiano escolar. Como lembra Foucault (1976), a partir dos referidos dispositivos o Ocidente organiza em torno do sexo técnicas religiosas, médicas e sociais de controle e punição, muitas dessas com a função de conservar a ordem social.

Vamos estabelecendo quem vigia quem, quem controla quem, enfim, vamos construindo identidades, tanto daqueles que devem estar num ponto do processo, quanto daqueles que se situam na outra extremidade, até que sejamos capazes de nos autovigiar, autocontrolar e autogovernar, incorporando as normas que muitas vezes não colocamos em discussão e naturalizamos. Como nos lembra Britzman (2000), a sexualidade não se constitui em problema, mas ela é o lugar em que os problemas se afixam. (FERRARI, 2010, p. 258).

Portanto, temos que atentar para o fato de que a sexualidade está sempre relacionada com a visão conservadora, com o problema do poder, com o sexo e com os dispositivos de sexualidade. Esses dispositivos atuam na constituição das identidades dos sujeitos, ou seja, na forma pela qual nos comportamos e construímos a consciência de nós mesmos.

A história do aluno Bernardo, narrada por nós, é um exemplo dessa realidade. Os insultos que alunxs e professorxs fazem a ele é uma manifestação da prática conservadora homofóbica na referida escola.

Ainda sobre a história de Bernardo, tivemos acesso a indícios de que possivelmente, a partir dos discursos produzidos pelxs suxs colegas, o jovem foi se sentindo crescentemente desconfortável em sua sala de aula, afinal ele era a mulherzinha e o bichinha. A prática discursiva conservadora desenvolvida no ambiente escolar levou o jovem a vivenciar processos de subjetivação que podem também ter influenciado seus processos de tessitura

\footnotetext{
${ }^{13}$ A noção de dispositivo tem uma função estratégica, tem o papel de anunciar uma nova concepção de poder. Foucault (2006) diz que o dispositivo determina a lógica do jogo que pode haver entre os elementos que possuem os discursos científicos, filosóficos, morais, instituições, leis para suplantar a dualidade entre as formações discursivas que representam o saber, e não discursivas, que representam o poder. Temos um dispositivo quando conseguimos isolar as estratégias presentes nas relações entre saberes e poderes. Os dispositivos são processos especiais e não possuem ordenações estáveis.
} 


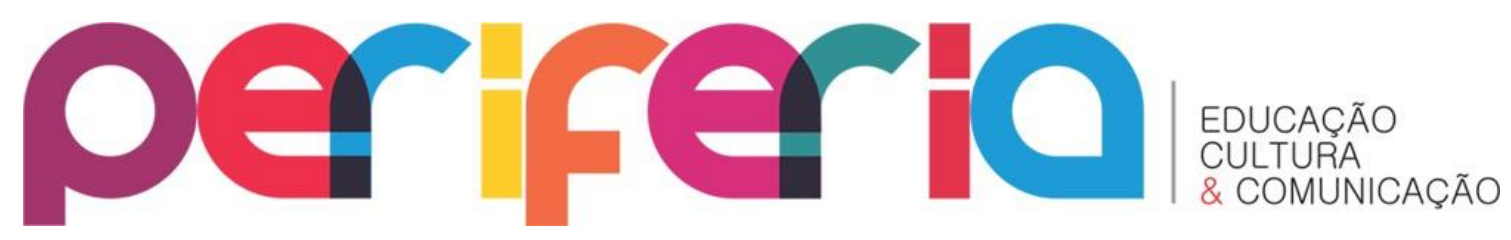

identitária. Outra pista é a de que Bernardo teria feito uso dos elementos do candomblé como meio de se contrapor aos colegas que o discriminavam ${ }^{14}$.

É importante enfatizar que nossa intenção aqui não é julgar a escola nem a professora de Bernardo. Decisões drásticas são tomadas por diferentes escolas e professorxs em diferentes circunstâncias, e sua propriedade como solução dos problemas não pode ser afirmada nem negada. Todavia, não podemos deixar de pontuar que o jovem foi vítima de práticas conservadoras preconceituosas, discriminatórias e possivelmente essas práticas influenciaram seus comportamentos e mesmo seus processos de constituição identitária.

Segundo Louro (2008), a escola é um local que indica e naturaliza quem são as alunas e os alunos que servirão de modelo a ser seguido e a não ser seguido. Esses modelos influenciam na constituição das identidades de todxs xs estudantes e um longo aprendizado vai colocando cada um em seu lugar. A situação vivida por Bernardo nos dá pistas de que sua orientação sexual não deveria servir de modelo para xs demais alunxs, o que deu origem aos problemas que enfrentou.

Por um aprendizado eficaz, continuado e sutil, um ritmo, uma cadência, uma disposição física, uma postura parecem penetrar nos sujeitos, ao mesmo tempo em que esses reagem e, envolvidos por tais dispositivos e práticas, constituem suas identidades "escolarizadas". Gestos, movimentos, sentidos são produzidos no espaço escolar e incorporados por meninos e meninas, tornando-se parte de seus corpos. Ali se aprende a olhar e a se olhar, se aprende a ouvir, a falar e a calar; se aprende a preferir. Todos os sentidos são treinados, fazendo com que cada um e cada uma conheça os sons, os cheiros e os sabores 'bons' e decentes e rejeite os indecentes; aprenda o que, a quem e como tocar (ou, na maior parte das vezes, não tocar) [...]. (LOURO, 2008, p. 61).

\footnotetext{
${ }^{14}$ É importante esclarecer que procuramos elementos para saber como realmente Bernardo se sentia. Marcamos com o jovem uma entrevista, contudo, na data marcada Bernardo não compareceu à escola. Marcamos outra data, porém, ele faltou novamente, o que nos levou a suspeitar que o jovem não queria ser entrevistado, e por isso não insistimos.
} 


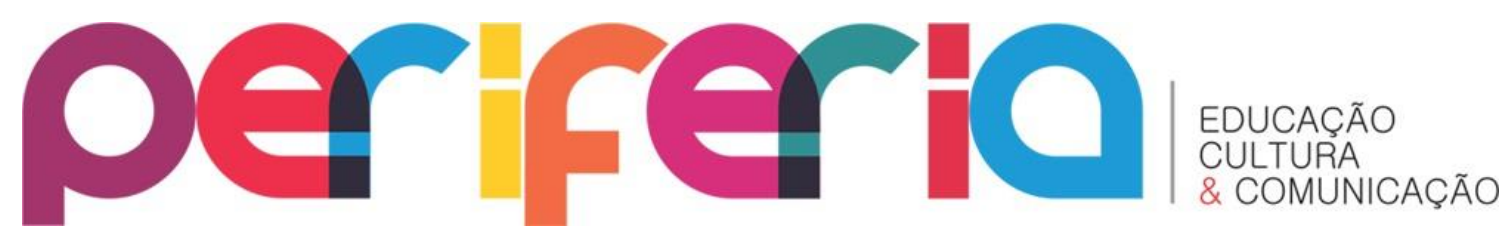

As marcas da escolarização se inscrevem, assim, na formação das identidades de todxs xs estudantes, pois todxs vão aprendendo o que é o metro-padrão, ou seja, o que é considerado normal em relação à sexualidade, ao peso, à etnia, à aparência física, à inteligência, etc. E quem foge $a$ isso passa a ser visto como $x$ anormal, $x$ diferente, o que pode produzir efeitos negativos sobre os processos de formação identitária. Mesmo xs estudantes que não são consideradxs “xs anormais" ou "xs diferentes”, vão aprendendo qual a sexualidade (aparência, inteligência, etc.) que serve como modelo e, assim, muitxs tecem seus processos identitários tentando não se distanciar do metro-padrão estabelecido.

No interior das escolas, as redes de poder estão presentes e se manifestam pelos regimes de verdade por meio dos discursos proferidos e pelas práticas conservadoras que formam o seu exercício. Passa-se a nomear o que é diferença é quem é $x$ diferente, ou o que é anormal e quem é $x$ anormal, ou seja, nessas instituições, como as relações de poder sempre estão presentes, a diferença também está, uma vez que esta é continuamente formada pelas relações de poder. Assim, podemos inferir que a escola por nós observada a partir de práticas conservadoras também produz as diferenças, possibilitando que discursos e procedimentos de perseguição e discriminação sejam direcionados a algunxs alunxs LGBTIS.

Diferenças, distinções, desigualdades... A escola entende disso. Na verdade, a escola produz isso. Desde seus inícios, a instituição escolar exerceu uma ação distintiva. Ela se incumbiu de separar os sujeitos - tornando aqueles que nela entravam distintos dos outros, os que a ela não tinham acesso. Ela dividiu também, internamente, os que lá estavam, através de múltiplos mecanismos de classificação, ordenamento, hierarquização. A escola que nos foi legada pela sociedade ocidental moderna começou por separar adultos de crianças, católicos de protestantes. Ela também se fez diferente para os ricos e para os pobres e ela imediatamente separou os meninos das meninas. Concebida inicialmente para receber alguns - mas não todos - ela foi, lentamente, sendo requisitada por aqueles/as aos/as quais havia sido negada. Ela precisou ser diversa: organização, currículos, prédios, 


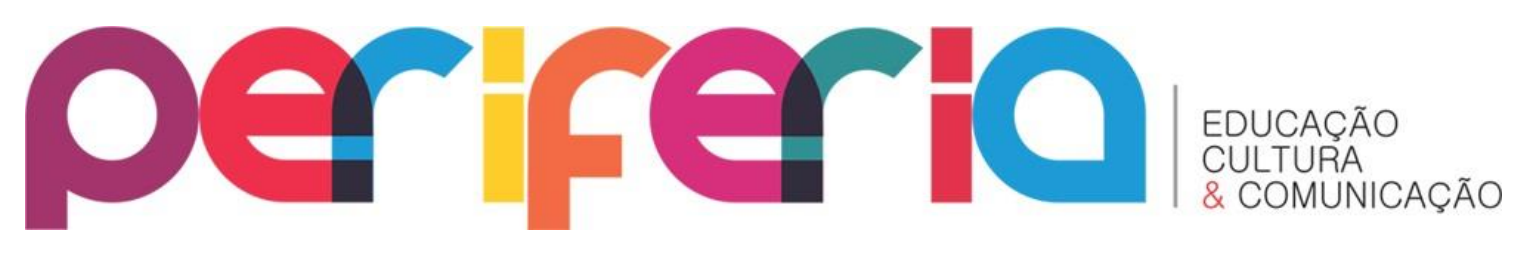

docentes, regulamentos, avaliação iriam, explícita ou implicitamente, "garantir" - e também produzir - as diferenças entre os sujeitos (LOURO, 2008, p. 57).

É importante sinalizar que as aprendizagens construídas nas escolas a partir das práticas conservadoras confirmam e também produzem diferenças. Todavia, as alunas e alunos não são somente passivos receptores dessas lições. Elas e eles reagem, reinventam, contestam, abandonam ou ostentam completamente essas construções, influenciando assim na tessitura de suas identidades. Bernardo, de certa forma, também reagiu e desenvolveu uma tática (CERTEAU, 2001) para poder lidar com a referida situação e, assim, não sucumbir perante as alunas e alunos que o discriminavam. Ele usou uma tática para subverter a ordem imposta e poder resistir a ela.

Foucault (2009) não fala em tática, mas em resistência. Todavia, as ideias se assemelham. Assim, segundo Foucault (2009), a reação de Bernardo pode ser vista como uma forma de resistência às práticas conservadoras e aos diferentes tipos de poder que se encontram em sua escola. Ou melhor dizendo, a sua reação refletiu uma forma de enfrentamento que se deu a partir do desenvolvimento de estratégias às práticas conservadoras e às diferentes formas de poder, ou seja, à visão conservadora e ao poder da escola que percebia que o aluno sofria perseguição e discriminação e nada fazia, e ao poder dxs demais alunxs que praticavam os atos de perseguição e discriminação. Quando o estudante amedrontava os colegas usando os elementos do candomblé, ele não estava somente reagindo, mas criando invenções de existências não padronizadas, como a invenção de si e de modos de conviver com xs demais estudantes da escola.

Naquele primeiro contato que tivemos com a escola, ficamos confusos com a fala da funcionária Maria, pois nos pareceu que ela dizia que o aluno não sofria discriminação por ser praticante do candomblé, mas por ser homossexual. Ela, por um lado, negava uma prática discriminatória, mas a confirmava por outro. Essa situação se apresentava como um indício de que havia uma prática conservadora de exclusão na instituição, pois o aluno era 


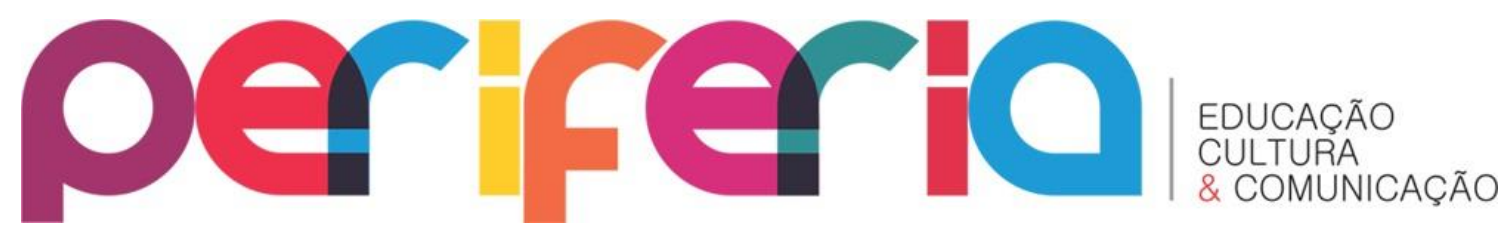

discriminado por ser homossexual, e nos parece, como já foi dito, que este desenvolveu uma tática, segundo a concepção de Certeau (2001), para poder lidar com a situação e, assim, não sucumbir perante as alunas e alunos que o descriminavam. 0 referido estudante usou uma tática para subverter a ordem imposta e poder resistir a ela. Segundo Certeau (2001, p. 47), essas táticas são gestadas em "maneiras de fazer" que se constituem em:

[...] vitórias do "fraco" sobre o mais "forte" (os poderosos, a doença, a violência das coisas ou de uma ordem, etc.), pequenos sucessos, artes de dar golpes, astúcias de "caçadores", [...] simulações polimorfas, achados que provocam euforia, tanto poéticos quanto bélicos. [...] Essas táticas manifestam igualmente a que ponto a inteligência é indissociável dos combates e dos prazeres cotidianos que articula.

Durante nossas observações no intervalo escolar acabamos conhecendo Bernardo. Víamos o aluno interagindo sempre com um mesmo grupo de meninas. Os meninos não se relacionavam muito com ele e alguns, quando o faziam, utilizavam de piadas e insultos, chamando-o de "viadão, viado, gayzão, gay, mulherzinha, boiolão, boiola e bichinha”.

[...] as expressões "veado nojento" (sapatão sem-vergonha) estão longe de ser simples palavras lançadas ao vento, mas agressões verbais que deixam marcas na consciência, traumas que se inscrevem na memória e no corpo (de fato, a timidez, o constrangimento e a vergonha são atitudes corporais resultantes da hostilidade do mundo exterior). E uma das consequências da injúria consiste em modelar a relação com os outros e com o mundo: portanto, em modelar a personalidade, a subjetividade e o próprio ser de um indivíduo. (ÉRIBON, apud BORRILLO, 2010, p. 25).

Contudo, é importante dizer que nem todxs xs alunxs LGBTIS reagem às práticas discursivas conservadoras e preconceituosas com timidez, constrangimento ou vergonha: alguns reagem sendo agressivos. O sujeito estigmatizado para se proteger pode apresentar comportamentos diferenciados, pode se retrair, tornar-se agressivo, indiferente... Tudo isso 


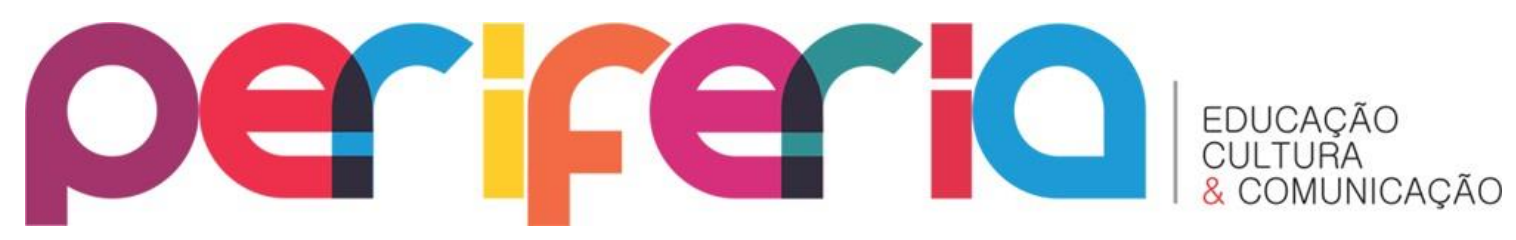

pode prejudicar seus processos de interação social e o desenvolvimento de seus processos identitários (GOFFMAN, 1988). Nas vezes em que presenciamos os insultos a Bernardo, ele sempre reagia fazendo uso das práticas discursivas agressivas como estratégias ou táticas contra aquelxs que tentavam enquadrar sua sexualidade dentro do metro-padrão heterossexual.

A história de Bernardo sinaliza que as escolas precisam incorporar a noção de diferença e a "disputa que, em vez de destruir o outro, lida com uma articulação provisória da diferença que reconhece a legitimidade da existência do outro" (MACEDO; PEREIRA, 2009). Ou seja, reconhecer x outrx passa por uma negociação em que as relações conservadoras e de poder estão presentes. A história desse aluno na escola nos dá pistas de que essa negociação não é pacífica, mas se dá numa luta política por legitimação do seu direito de ser diferente.

A ideia de movimento, de articulação de diferenças, de emergência de configurações culturais baseadas em contribuições de experiências e de histórias distintas tem levado a explorar as possibilidades emancipatórias [...], alimentando os debates e iniciativas sobre novas definições de direitos, de identidades, de justiça e cidadania. (SANTOS, 2003, p. 33).

Esses debates e iniciativas têm possibilitado novas compreensões do que vem a ser a cidadania, de uma cidadania fundamentada no reconhecimento da diferença e na criação de políticas sociais direcionadas para o combate ao conservadorismo e para a redução das desigualdades. Essa nova maneira de se pensar a cidadania solicita a interferência de procedimentos dialógicos de tessitura de novas formas de intervenção política.

Neles são explorados os potenciais e os limites dessas experiências como iniciativas emancipatórias e caminhos para cidadanias ativas. Estas procuram articular o reconhecimento da diferença e a luta pela igualdade e pela redistribuição segundo princípios de justiça e constelações de direitos atentos à diversidade dos atores e dos contextos e à 


\section{periferio}

interseção de diferentes escalas: local, nacional e global. (SANTOS, 2003, p. 44).

Assim, podemos entender que o comportamento agressivo que Bernardo se apresentava - frente aos discursos e práticas conservadoras dxs professorxs e colegas de escola que o subjetivavam como um deficiente social - como uma resistência política, uma oposição aos vários procedimentos de discriminação e desqualificação dos quais foi vítima. Novamente, encontramos eco no pensamento de Foucault (2006), pois a história desse jovem evidencia que na referida escola a sexualidade está relacionada com a questão do poder. As práticas conservadoras e os dispositivos de sexualidade presentes nessa instituição atuam, também, na constituição das identidades do jovem, em seus comportamentos, e influenciam na consciência que ele vai tecendo de si próprio. São processos complexos nos quais ficam explicitados os modos como os processos de subjetivação vão sendo desenvolvidos a partir, e apesar, de mecanismos conservadores de regulação.

\section{CONSIDERAÇÕES FINAIS}

Após analisar o material da pesquisa, consideramos importante salientar que as professoras e os professores precisam perceber a importância de saber lidar com as manifestações da diferença. Para isso, é necessário nos colocarmos numa atitude de curiosidade, de diálogo, de compreensão e, acima de tudo, questionar os nossos próprios padrões de conhecimento e de valores, a fim de que possamos entender $x$ outrx e trabalharmos com esse outrx como legítimo outrx (MATURANA, 1999), como parte de uma ação política de democratização do espaço escolar. Esta é uma parte de uma luta árdua e importante a se fazer, se temos como meta o respeito à diferença e à pluralidade humana como condição de construção de uma sociedade democrática.

Assim, é importante dizermos a importância da luta, saber que ela é difícil e bastante longa. Não adianta simplesmente apontar o que falta nas 


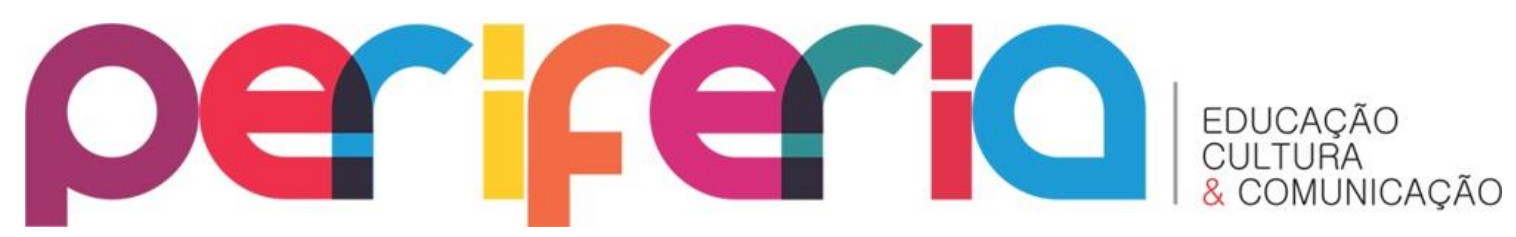

escolas para que se desenvolvam práticas democráticas emancipatórias, é preciso lutar, é preciso que encontremos caminhos possíveis para a tessitura de ações emancipatórias. Toda conquista democrática é o resultado de lutas que foram travadas contra o pensamento conservador, contra os poderes instituídos e suas formas de legitimação (SANTOS, 2009). Dessa forma, continuaremos lutando, pois ela é processual e, portanto, sem fim.

\section{REFERÊNCIAS}

BORRILO, D. Homofobia: história e crítica de um preconceito. Belo Horizonte: Autentica, 2010.

BAUMAN, Z. Identidade. Rio de Janeiro: Jorge Zahar, 2005.

CERTEAU, M. de. A invenção do cotidiano: artes de fazer. Petrópolis, RJ: Vozes, 2001.

FERRARI, A. Você já deve saber sobre minha "orientação sexual” (se não sabia, ficou sabendo agora, hehe) - subjetividades e sujeitos em negociação. In: FERRARI, A. Sujeitos, subjetividades e Educação. Juiz de Fora: UFJF, 2010.

FOUCAULT, M. O Ocidente e a verdade do sexo. [S.l.: s.n.], 1976. Disponível em: <http://filoesco.unb.br/foucault/ ocidente.pdf>. Acesso em: 27 jan. 2012. . A ordem do discurso. São Paulo: Loyola, 1996. 2006.vol. 4.

Ditos e escritos: estratégia - poder e saber. Rio de Janeiro: Forense, . Dois ensaios sobre o sujeito e o poder.[S.l.: s.n.], 2009. Disponível em: <http://filoesco.unb.br/foucault/ sujeitopoder.pdf>. Acesso em: 25jun. 2017. . Os Anormais. São Paulo: Martins Fontes, 2011.

GINZBURG, C. Mitos, emblemas e sinais. São Paulo: Companhia das Letras, 1989.

GOFFMAN, E. Estigma: notas sobre a manipulação da identidade deteriorada. Rio de Janeiro: LTC, 1988.

HIRSCHMAN, A. A retórica da intransigência: perversidade, futilidade, ameaça. São Paulo: Companhia das Letras, 1992. 


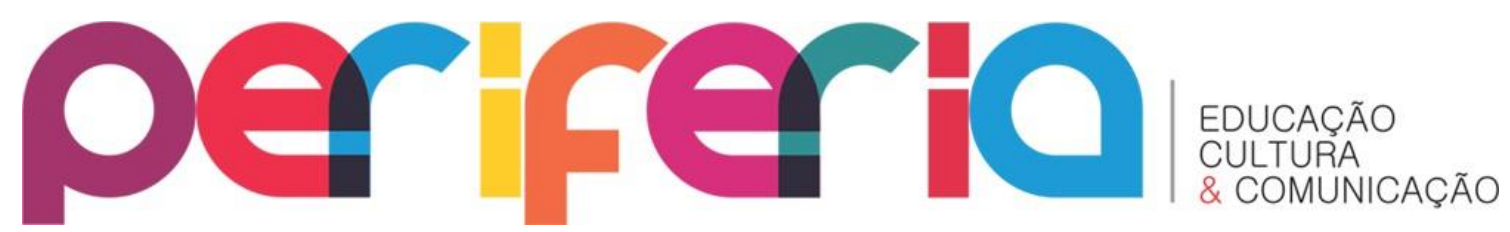

LOURO, G. L. Gênero, sexualidade e educação: uma perspectiva pósestruturalista. Petrópolis, RJ: Vozes, 2008.

MACEDO, E. F.; PEREIRA, M. Z. C. Currículo e diferença no contexto global. In: PEREIRA, M.Z. da C.; CARVALHO, M. E. P.; PORTO, R. de C. C. Globalização, interculturalidade e currículo na cena escolar. Campinas, SP: Alínea, 2009.

MANNHEIM, K. O pensamento conservador. Texto Original: MANNHEIM, K. Essays on Sociology and Social Psychology . Londes: Routledge and Kegan Paul Ltd., 1959, pp. 74-119. Tradução de Sylvia Lyra.

MATURANA, H. Emoções e linguagens na Educação e na Política. Belo Horizonte: Editora UFMG, 1999.

SANTOS, B. de S. Pela mão de Alice: o social e o político na pós-modernidade. São Paulo: Cortez, 2001.

Reconhecer para libertar: os caminhos do cosmopolitismo multicultural. Rio de Janeiro: Civilização Brasileira, 2003.

Democratizar a democracia: os caminhos da democracia participativa. Rio de Janeiro: Civilização Brasileira, 2009. 